\title{
Hippocampal IGF-1 expression, neurogenesis and slowed aging: clues to longevity from mutant mice
}

\author{
Liou Y. Sun
}

Received: 1 November 2005 / Accepted: 1 December 2005

(C) Springer Science + Business Media B.V. 2006

\begin{abstract}
Recent studies point out the important role of IGF and insulin-related signaling pathways in the control of longevity of laboratory animals. The Ames dwarf mouse is a murine model of circulating GH and IGF-1 deficiency that exhibits dwarf phenotype characteristics and significantly extends lifespan. It is interesting to know that Ames dwarf mice do not experience an age-related decline in cognitive function when compared to their young counterparts. In this study, the most recent works on local GH and IGF-1 expression in the hippocampus of Ames mice are briefly reviewed.
\end{abstract}

Key words growth hormone $\cdot$ insulin-like growth factor I thymidine analogue 5'-bromo-2deoxyuridine - subgranular zone - dentate gyrus · pituitary-specific transcription factor · granule cell layer

\section{Abbreviations \\ GH growth hormone \\ IGF-1 insulin-like growth factor I \\ BrdU thymidine analogue 5'-bromo-2- deoxyuridine}

SGZ subgranular zone

DG dentate gyrus

Pit-1 pituitary-specific transcription factor

GCL granule cell layer

\section{Introduction}

Aging is a multi-factorial process that adversely affects the fitness of adult organisms over time, ultimately leading to death. Although the mechanisms underlying age-related degeneration and death in various species need to be identified, an evolutionally conserved pathway has begun to emerge (Kirkwood and Austad 2000). Ample recent evidence, mostly obtained from short-lived invertebrate organisms (e.g., Drosophila melanogaster and Caenorhabditis elegans), supports the evolutionary theory of aging, which subsequently has become an important basis for addressing the question of how we age (Guarente and Kenyon 2000). Studies in model organisms have begun to map out important genes and pathways that seem to regulate the pace of aging and are remarkably conserved from yeast to mice (Tatar et al. 2003). Interestingly, most of these "longevity genes" are found to be involved in the control of identifiable signaling pathways that can be activated by environmental stimuli and influence life history traits related to stress resistance, diapause, reproduction and life expectancy (Tatar 
et al. 2003). Perturbation of neuroendocrine signals, especially insulin-like growth factor-1 (IGF-1), is closely associated with changes in animal lifespan and age-dependent function (Tatar et al. 2003).

In invertebrates, reduced insulin/IGF signaling pathway significantly increased adult lifespan (Tatar et al. 2003; Guarente and Kenyon 2000). In mice, mutations of transcription factors Prop1 and Pit 1 impede pituitary production of growth hormone, thyroid-stimulating hormone and prolactin; reduce growth rate and adult body size; and increase adult lifespan by $40 \%$ to $60 \%$ (Bartke 2000; Flurkey et al. 2001). Mice with mutation of growth hormone receptor (GHRKO) have similar extension of lifespan (Zhou et al. 1997). Expressed throughout life, these mutations produce many secondary alterations in endocrine systems, including profound suppression of circulating IGF-1. Furthermore, mice heterozygous for the disruption of IGF-1 receptor IGF1r (IGF1r+/-) also live longer than wild-type controls (Holzenberger et al. 2003). Interestingly, caloric restriction is well documented to delay aging and prolong life in laboratory animals. In caloric-restricted animals, plasma IGF-1 levels were reduced (Bartke et al. 2003).

Besides the essential role of regulating somatic growth and development, insulin-like growth factor-1 is also important in neuronal function. During development of the nervous system, IGF-1 plays a prominent neurotrophic role, stimulating differentiation and survival of specific neuronal populations (Wilkins et al. 2001; Vicario-Abejon et al. 2003). In the adult central nervous system (CNS), IGF-1 is a neuromodulator and is involved in regulation of synaptic plasticity (Torres-Aleman 1999). IGF-1 levels are reduced with age. Restoring IGF-1 levels was reported to enhance neurogenesis and ameliorate the age-related cognitive malfunction in aged brain (Markowska et al. 1998). Furthermore, in transgenic mice with increased expression of IGF-1 in the brain, the weight and volume of the brain are increased substantially due to increases in neuron number and total myelin (D'Ercole et al. 2002), whereas transgenic mice with ectopic brain expression of IGFBP-1, an inhibitor of IGF action, and mice with ablated
IGF-1 gene expression have brain growth retardation with impaired neuronal somatic and dendritic growth (D'Ercole et al. 2002; Cheng et al. 2003). Further, IGF-1 gene deletion in humans is associated with mental retardation (Woods et al. 1996).

The Ames dwarf mouse is a murine model of circulating GH and IGF-1 deficiency that exhibits dwarf phenotype characteristics and significantly extended lifespan, the result of a homozygous mutation at the Prop-1 locus on chromosome 11 (Bartke 2005; Brown-Borg et al. 1996). Surprisingly, in addition to extended lifespan and delayed physical aging, Ames dwarf mice do not experience an age-related decline in cognitive function when compared with their young counterparts, as measured in behavioral tests (Kinney et al. 2001b). The results of our recent work show that genetically GH deficient Ames dwarf mice have elevated levels of IGF-1 in the hippocampus, while the level of the corresponding mRNA is as high as in normal mice (Sun et al. 2005a, b).

\section{Aging and hippocampal neurogenesis}

Cognitive functions show many alternative outcomes during aging (Kirkwood and Austad 2000). Individual trajectories range from the devastating effects of Alzheimer's disease (AD) and multiinfarct dementia (MID) to very mild changes detected during middle-age that may become more pronounced in later life without interfering with most daily activities. The hippocampal formation, a temporal lobe brain structure involved in various types of learning and memory, has been implicated in age-related memory dysfunction. Its functional integrity is critical for normal memory function, and it is very vulnerable to the process of aging (Jarrard 1995; Driscoll and Sutherland 2005). The ability to learn new tasks decreases with age, particularly in spatial memory (Driscoll and Sutherland 2005). At the cellular level, synaptic contacts, synaptic strength and plasticity are reduced during aging (Barnes 1994). Furthermore, the cognitive impairment is associated with deterioration of hippocampal circuitry and plasticity (Smith et al. 2000), suggesting that the age-associated spatial learning 
impairment might be explained by deficiencies in hippocampal spatial information processing.

Studies of the hippocampus reveal a number of types of structural plasticity, including neurogenesis in the dentate gyrus, remodeling of dendrites and the formation and replacement of synapses. These changes, along with compensatory neurochemical and neuroendocrine responses, provide the brain with a considerable amount of resilience. Within the hippocampus there are several cellular types, including large principal pyramidal and nonprincipal cells of the CA regions (Gage 2000) and small granule neurons of the dentate gyrus (DG). One of the most exciting neuroscience discoveries of the past decade is the birth of new neurons that occur in discrete regions of the adult mammalian brain, namely the subgranular zone (SGZ) of the hippocampal dentate gyrus and in the subventricular zone (SVZ) (Altman and Das 1965, 1966; Gage 2000). In these regions, regulation of adult neurogenesis is often demonstrated by systemic injection of an exogenous synthetic S-phase marker such as bromo-deoxyuridine (BrdU), the thymidine analogue, which is taken up by dividing cells during the S-phase (Miller and Nowakowski 1988). This technique has shown that neural progenitor cells arising from the subgranular zone migrate into the granule cell layer (GCL) where they differentiate into new neurons and integrate into the local network, receiving afferents and sending out functional efferents (Cameron et al. 1993), whereas SVZborn neurons are destined for the olfactory bulb (OB) (Seaberg and van Der 2003). The process of neurogenesis in the adult dentate gyrus can be divided into three distinct phases. First, neural precursor cells that reside at the border between the hilus and the granule cell layer undergo cell division. Second, newborn cells begin to migrate into the GCL and extend neuronal processes. Third, the cells integrate into the GCL and begin to express the neuronal marker. These newly born neurons have electrophysiological properties of mature neurons, conduct action potentials, and make functional synapses with the adult granule cell (van Praag et al. 2002). It has also been suggested that newly generated neurons in adulthood may have an important physiological role, because blockade of hippocampal neurogenesis is reported to inhibit hippocampus-dependent learning (Shors et al. 2001), and because reducing the population of new interneurons in the OB impairs odor discrimination (Gheusi et al. 2000).

Neurogenesis in the dentate gyrus occurs throughout the lifespan, but decreases with age in rats, mice, monkeys and humans (Zitnik and Martin 2002; Cameron and McKay 1999; Gould et al. 1999). Several studies have suggested that cognitive decline in aging may be attributable to decreased dentate gyrus neurogenesis (Shors et al. 2001; Drapeau et al. 2003). Conversely, hippocampal neurogenesis was reported to increase in aged mice living in an enriched environment (Kempermann et al. 2002). Enhanced neurogenesis is accompanied by improved learning, exploratory behavior and locomotor activity (Kempermann et al. 2002). Therefore, it is suggested that restoring hippocampal neurogenesis may be a strategy for reversing age-related cerebral dysfunction. In addition, growth factors stimulate proliferation of neuronal precursors in the adult brain in vitro and in vivo. For example, fibroblast growth factor (FGF)-2 is expressed in adult rodent SVZ and SGZ (Goldman 1998), and intracerebroventricular (ICV) infusions of FGF-2 upregulate dentate neurogenesis considerably in the aged brain and also increase neurogenesis in SVZ and neuronal migration to OB (Kuhn et al. 1997; Jin et al. 2003).

Insulin-like growth factor-1 is another interesting component that stimulates neurogenesis, via a pattern of regulation across lifespan (Anderson et al. 2002). IGF-1 is a $7.5 \mathrm{kDa}$ protein, and yet it can be taken up into CSF by a process that is independent of IGF receptors or binding proteins (Pulford and Ishii 2001). In rodents, voluntary exercise in a running wheel has been reported to increase neurogenesis in the dentate gyrus (van Praag et al. 2002). Such exercise increases the uptake of IGF-1 from the blood and activates c-fos protein expression in dentate gyrus and other brain regions in a manner that is mimicked by IGF-1 administration into the circulation (Carro et al. 2000). Moreover, immunoneutralization of IGF-1 blocks the effects of exercise to enhance neurogenesis (Trejo et al. 2001). Block- 
ade of IGF-1 has also been shown to prevent exercise-induced neurogenesis, demonstrating IGF-1 as a necessary component of physical activity-induced neurogenesis (Trejo et al. 2001).

\section{IGF-1 expression and actions in the central nervous system}

In the murine brain IGF-1 expression begins at approximately embryonic day 14, peaks in the second postnatal week, and then declines but continues throughout life (D'Ercole et al. 1996). IGF-1 mRNA expression is predominately located in neurons and astrocytes and, to a lesser extent, in oligodendrocytes and their precursors (Shinar and McMorris 1995). Because IGF-1 mRNA is detected in the subventricular zone during early development (Bartlett et al. 1992), IGF-1 may also be expressed by neural stem cells and early glial progenitors. As CNS development progresses, regional IGF-1 expression often peaks concurrently with the proliferation of neural cells. In addition, this expression occurs immediately prior to the peak time of myelinspecific protein gene expression and rapid myelination (Sorg et al. 1987; Campagnoni and Macklin 1988). The type-1 IGF receptor, which is the predominant, if not exclusive, mediator of IGF-1 actions, is expressed by neuronal stem cells (Brooker et al. 2000) and subsequently appears to be expressed in all neural cells. These studies strongly indicate that IGF-1 plays an important role in CNS development by acting in an autocrine and/or paracrine fashion. In addition, a variety of insults that result in CNS demyelination induce IGF-1 gene expression near or at the sites of injury (Gehrmann et al. 1994; Yao et al. 1995), suggesting a role for IGF-1 in protecting oligodendrocytes from injury and/or in promoting their regeneration following injury.

The brain requires enormous supplies of fuel to support neuroglial growth and process formation during early postnatal development. Murine and human brains consume over half the energy available to the organism as a whole during this critical period (Gibbons 1998), while undernutrition may result in permanent intellectual deficit (Chase and Martin 1970). How the developing brain competes so successfully with peripheral tissues for resources is unknown. Insulin preferentially enhances fuel and substrate utilization by peripheral tissues but does not seem to be involved in the regulation of brain metabolism (Baskin et al. 1987). Very little insulin is synthesized within the brain (Baskin et al. 1987) and little circulating insulin can cross the blood-brain barrier (Reinhardt and Bondy 1994). However, IGF-1 is abundant in the developing brain, where it is concentrated in large projection neurons (Bondy 1991). IGF-1 and insulin receptors are also homologous, with nearly identical signaltransducing domains engaging many of the same intracellular pathways. Recent studies suggest that endogenous brain IGF-1 may play an essential, insulin-like role in brain glucose metabolism (Cheng et al. 2000).

In vitro studies have shown that IGF-1 stimulates the proliferation of neuron progenitors, induces the differentiation of oligodendrocytes, and increases the survival of neurons and oligodendrocytes (see review in D'Ercole et al. 2002). IGF-1 effects on CNS suggested by in vitro studies have been confirmed in vivo. Multiple lines of mice with genomic alterations in their IGF systems have been generated. IGF-1 overexpressing mice were among the first transgenic mice generated (Mathews et al. 1988). Depending upon the tissues and magnitude of transgene expression among the transgenic mice, postnatal somatic overgrowth begins at 3-4 weeks of age and leads to a moderate increase in weight by early adulthood. The IGF-1 transgenic mice exhibit disproportional overgrowth of some organs, most remarkably of the brain (D'Ercole et al. 2002). Interestingly, transgenic mice with larger brain weights usually do not exhibit somatic overgrowth; rather they have modestly reduced adult body weight and similarly reduced serum IGF-1 levels (Ye et al. 1995).

Recently, by the use of a variety of promoters aimed at generating organ- or tissue-specific IGF1 overexpression, a number of other IGF-1 transgenic mice have been created (D'Ercole et al. 2002). At the same time, generation and study of mice with IGF-1 and the IGF-1 receptor null mutation are providing direct evidence of the central role of IGF-1 in somatic growth 
(Efstratiadis 1998). Mice with disrupted IGF-1 and IGF-R gene exhibit marked in utero and postnatal growth retardation and have reduced survival past birth (Liu et al. 1993; Baker et al. 1993; Powell-Braxton et al. 1993). The brains of IGF-1 knockout (KO) and IGF-1R KO mice are smaller than those of controls, although the brains are not as growth-retarded as the body weights, and the brain phenotype in each appears to be similar. IGFBP-1 is an inhibitor of IGF action and would be expected to inhibit the actions of endogenous IGF-1 and IGF-1I. Using different promoters, several groups have created IGFBP-1 transgenic mice. These transgenic mice exhibit somatic and brain growth retardation (D'Ercole et al. 1994; Dai et al. 1994). Collectively, these studies provided compelling evidence that IGF-1 promotes growth of the brain by increasing neuron number, process outgrowth and synaptogenesis. IGF-1 acts to increase neuron number by increasing the rate of neuron proliferation while inhibiting apoptosis in place of naturally occurring neuron death, suggesting its neuronal protective action. Some regions of the brain, notably the hippocampus dentate gyrus, appear to have a greater dependency on the growth-promoting effect of IGF-1.

Levels of IGF-1 and the type-1 IGF receptor decrease in several regions of the brain during normal aging (Sonntag et al. 1995), and administration of IGF-1 can counteract some age-related changes in brain energy metabolism and function (Lynch et al. 2001). Recent evidence that IGF-1 signaling is involved in the development of Alzheimer's diseases (ADs) are gaining attention (Carro and Torres-Aleman 2004; Carro et al. 2005). High brain amyloid-beta levels are found at an early age in mutant mice with low circulating IGF-1, and amyloid-beta burden can be reduced in aging rats by increasing serum IGF-1 (Carro and Torres-Aleman 2004). Tau phosphorylation, which causes the formation of neurofibrillary tangles and senile plaques in $\mathrm{AD}$, was dramatically increased in the brain of IGF1-/mice (Cheng et al. 2005). This evidence suggests that IGF-1 can protect neurons against insults relevant to the pathogenesis of Alzheimer's disease, stroke and other age-related neurological disorders and can enhance learning and memory.
Adult neurogenesis in the long-lived mutant mice

Ames dwarf mice

The first mammalian mutant found to have an increased average and maximal lifespan was the Ames dwarf mouse (Bartke et al. 2001, 2003; Brown-Borg et al. 1996). Depending on gender and genetic background, extensions of about $50 \%$ in average lifespan and $40 \%$ in maximal lifespan are observed (Brown-Borg et al. 1996). The Ames dwarf mouse is of considerable significance: clinical evidence suggests that humans with mutated Prop1 may show increased longevity (Krzisnik et al. 1999; Rosenbloom et al. 1999). Ames dwarf mice display phenotypes of dwarfism (they are about one-third normal size), reduced growth rate, and deficiencies in circulating $\mathrm{GH}$, prolactin, thyroid-stimulating hormone (TSH) and IGF-1 (Bartke et al. 2001, 2003; Brown-Borg et al. 1996). Males exhibit variable fertility, but females are infertile as a result of a lack of prolactin (treatment with prolactin restores fertility) (Bartke et al. 2003). Both genders display delayed reproductive maturity (Bartke et al. 2001; Brown-Borg et al. 1996). A number of aging-related phenotypes are also delayed, including fatal neoplastic disease and declines in immune function, locomotor activity, learning and memory (Ikeno et al. 2003; Kinney et al. 2001b).

Caloric restriction treatment of Ames mice results in a further lifespan extension, indicating separate (though probably not fully independent) underlying mechanisms (Bartke et al. 2001). A mechanistic difference is also suggested by the observation that $\mathrm{CR}$ decelerates aging (the slope of the mortality curve decreases), whereas the mutation in Prop1 delays it (the mortality curve shifts to the right but maintains its shape) (Bartke et al. 2001). Moreover, effects of Ames dwarfism and $\mathrm{CR}$ on gene expression profiles and on expression of insulin-related genes are not the same (Masternak et al. 2004).

\section{GHR-KO mice}

GHR-KO mice (Laron dwarf mice) lack a growth hormone receptor (GHR) because of a disrupted 
GHR/binding protein $(\mathrm{GHR} / \mathrm{BP})$ gene and are thus GH resistant (Zhou et al. 1997). These mice were generated to model the complete $\mathrm{GH}$ deficiency seen in human Laron syndrome. Laron syndrome, a recessively inherited disease with $\mathrm{GH}$ resistance, is characterized by very short stature, facial dysmorphism, truncal obesity, delayed puberty, recurrent hypoglycemia, low serum IGF-1 concentrations, elevated serum $\mathrm{GH}$ levels, absent, low, or dysfunctional serum GH-binding protein, and resistance to $\mathrm{GH}$ in patients (Laron 2002). As in human patients, growth is stunted in GHR-KO mice (adults are half the size of wild-type adults), and concentrations of circulating IGF-1 are very low to undetectable (Zhou et al. 1997). The lack of negative feedback of IGF-1 on GH secretion results in higher concentrations of circulating GH. Prolactin levels are also elevated. Plasma insulin and glucose concentrations are lower than normal in the GHR-KO mice, but insulin responsiveness is augmented, and reduced insulin release causes lowered glucose tolerance (Coschigano et al. 2000; Zhou et al. 1997).

Comparing mouse phenotypes

Interestingly, these two types of long-lived mutant mice exhibit delayed age-related cognitive decline while experiencing significant increase in both average and maximum life spans (Kinney et al. 2001a, b; Bartke et al. 2001). There is an apparent contradiction between the evidence that those long-lived mutant mice with a circulating GH/IGF-1 deficiency have normal or improved cognitive function and the evidence that a decrease of GH and IGF-1 expression is related to cognitive malfunction. Interestingly, recent findings showed that both hippocampal $\mathrm{GH}$ and IGF-1 protein levels were increased and the corresponding mRNAs were normal in Ames dwarf as compared with normal mice (Sun et al. 2005a, b).

Given the previous evidence that circulating IGF-1 is undetectable in Ames dwarf mice, the IGF-1 immunoreactivity detected by Western blot in the hippocampus seems unlikely to be derived from peripheral circulation and transport across the blood-brain barrier. Thus, IGF-1 might be produced locally in the hippocampus and might also act directly on the neuronal progenitor cells in the DG (Sun et al. 2005a). Increased phosphorylation of Akt and cyclic AMP responsive element-binding protein (CREB) were detected in the hippocampus of aged Ames dwarf mice (Sun et al. 2005a). Evidence of activation of the anti-apoptosis signal transduction cascade was also found in the hippocampus of old dwarf mice (unpublished data). These data support the hypothesis that increase in hippocampal GH and IGF-1 protein expression and subsequent activation of PI3K/Akt-CREB and activation of anti-apoptosis signals might contribute to the maintenance of cognitive function and is likely to be responsible for the integrity of neuronal structure and maintenance of youthful levels of cognitive function in these long-lived mice during aging.

Evidence of increased hippocampal neurogenesis was found in the young adult Ames dwarf mice (Sun et al. 2005b). BrdU labeling studies showed an increase in numbers of newly generated cells (BrdU positive) and newborn neurons (neuronal nuclear antigen and BrdU positive) in the dentate gyrus of dwarfs compared with normal mice at 3 months of age (Sun et al. 2005b). Furthermore, there was a dramatic reduction of BrdU positive cells in the DG areas of both aged dwarf and normal mice, indicating an age-dependent decline of hippocampal neurogenesis.

In addition, there was no significant difference in the total number of BrdU-labeled cells between aged dwarf and normal mice (unpublished data). However, interestingly, the total number of newly generated neurons (BrdU and NeuN double positive) in old dwarf mice was significantly greater than in old normal mice (unpublished data). Considering the evidence for a significant increase in hippocampal IGF-1 protein expression and activation of an anti-apoptosis signal transduction cascade, it is likely that the increase in the fraction of newborn neurons in aged dwarf mice was due, at least in part, to an effect of local IGF-1 on cell survival.

Taking these data together, we speculate that aging influences the balance between neurogen- 
esis and apoptosis in the mouse hippocampus as well as the process of the differentiation of the neuronal progenitors. Locally produced IGF-1 might work primarily as a promoting factor to increase neurogenesis in the DG area of the hippocampus in early adulthood; however, it functions mainly as a survival factor in the central nervous system to inhibit neuronal death during aging.

Acknowledgments This work was supported by Glenn Foundation/AFAR Scholarships and by Southern Illinois University Geriatrics Medicine and Research Initiative. The author thanks Dr. Andrzej Bartke for his suggestions and comments on this manuscript.

\section{References}

Altman J, Das GD (1965) Autoradiographic and histological evidence of postnatal hippocampal neurogenesis in rats. J Comp Neurol 124:319-335

Altman J, Das GD (1966) Autoradiographic and histological studies of postnatal neurogenesis. I. A longitudinal investigation of the kinetics, migration and transformation of cells incorporating tritiated thymidine in neonate rats, with special reference to postnatal neurogenesis in some brain regions. J Comp Neurol 126:337-389

Anderson MF, Aberg MA, Nilsson M, Eriksson PS (2002) Insulin-like growth factor-I and neurogenesis in the adult mammalian brain. Brain Res Dev Brain Res 134:115-122

Baker J, Liu JP, Robertson EJ, Efstratiadis A (1993) Role of insulin-like growth factors in embryonic and postnatal growth. Cell 75:73-82

Barnes CA (1994) Normal aging: regionally specific changes in hippocampal synaptic transmission. Trends Neurosci 17:13-18

Bartke A (2000) Delayed aging in Ames dwarf mice. Relationships to endocrine function and body size. In: Hekimi S (ed) The molecular genetics of aging. Springer, pp 181-202

Bartke A (2005) Minireview: role of the growth hormone/ insulin-like growth factor system in mammalian aging. Endocrinology 146:3718-3723

Bartke A, Coschigano K, Kopchick J, Chandrashekar V, Mattison J, Kinney B, Hauck S (2001) Genes that prolong life: relationships of growth hormone and growth to aging and life span. J Gerontol A Biol Sci Med Sci 56:B340-B349

Bartke A, Chandrashekar V, Dominici F, Turyn D, Kinney B, Steger R, Kopchick JJ (2003) Insulin-like growth factor 1 (IGF-1) and aging: controversies and new insights. Biogerontology 4:1-8

Bartlett WP, Li XS, Williams M (1992) Expression of IGF-1 mRNA in the murine subventricular zone during postnatal development. Brain Res Mol Brain Res 12:285-291

Baskin DG, Figlewicz DP, Woods SC, Porte D Jr, Dorsa DM (1987) Insulin in the brain. Annu Rev Physiol 49:335-347

Bondy CA (1991) Transient IGF-I gene expression during the maturation of functionally related central projection neurons. J Neurosci 11:3442-3455

Brooker GJ, Kalloniatis M, Russo VC, Murphy M, Werther GA, Bartlett PF (2000) Endogenous IGF-1 regulates the neuronal differentiation of adult stem cells. J Neurosci Res 59:332-341

Brown-Borg HM, Borg KE, Meliska CJ, Bartke A (1996) Dwarf mice and the ageing process. Nature 384:33

Cameron HA, McKay RD (1999) Restoring production of hippocampal neurons in old age. Nat Neurosci 2:894897

Cameron HA, Woolley CS, McEwen BS, Gould E (1993) Differentiation of newly born neurons and glia in the dentate gyrus of the adult rat. Neuroscience 56:337344

Campagnoni AT, Macklin WB (1988) Cellular and molecular aspects of myelin protein gene expression. Mol Neurobiol 2:41-89

Carro E, Torres-Aleman I (2004) Insulin-like growth factor I and Alzheimer's disease: therapeutic prospects? Expert Rev Neurother 4:79-86

Carro E, Nunez A, Busiguina S, Torres-Aleman I (2000) Circulating insulin-like growth factor I mediates effects of exercise on the brain. J Neurosci 20:29262933

Carro E, Trejo JL, Gerber A, Loetscher H, Torrado J, Metzger F, Torres-Aleman I (2005, September 22) Therapeutic actions of insulin-like growth factor I on APP/PS2 mice with severe brain amyloidosis. Neurobiol Aging [Epub ahead of print]

Chase HP, Martin HP (1970) Undernutrition and child development. N Engl J Med 282:933-939

Cheng CM, Reinhardt RR, Lee WH, Joncas G, Patel SC, Bondy CA (2000) Insulin-like growth factor 1 regulates developing brain glucose metabolism. Proc Natl Acad Sci USA 97:10236-10241

Cheng CM, Mervis RF, Niu SL, Salem N Jr, Witters LA, Tseng V, Reinhardt R, Bondy CA (2003) Insulin-like growth factor 1 is essential for normal dendritic growth. J Neurosci Res 73:1-9

Cheng CM, Tseng V, Wang J, Wang D, Matyakhina L, Bondy CA (2005) Tau is hyper-phosphorylated in the IGF1 null brain. Endocrinology 146:5086-5091

Coschigano KT, Clemmons D, Bellush LL, Kopchick JJ (2000) Assessment of growth parameters and life span of GHR/BP gene-disrupted mice. Endocrinology 141:2608-2613

Dai Z, Xing Y, Boney CM, Clemmons DR, D'Ercole AJ (1994) Human insulin-like growth factor-binding protein-1 (hIGFBP-1) in transgenic mice: characterization and insights into the regulation of IGFBP-1 expression. Endocrinology 135:1316-1327

D'Ercole AJ, Dai Z, Xing Y, Boney C, Wilkie MB, Lauder JM, Han VK, Clemmons DR (1994) Brain growth retardation due to the expression of human insulin like 
growth factor binding protein-1 in transgenic mice: an in vivo model for the analysis of igf function in the brain. Brain Res Dev Brain Res 82:213-222

D'Ercole AJ, Ye P, Calikoglu AS, Gutierrez-Ospina G (1996) The role of the insulin-like growth factors in the central nervous system. Mol Neurobiol 13:227-255

D'Ercole AJ, Ye P, O'Kusky JR (2002, Apr-Jun) Mutant mouse models of insulin-like growth factor actions in the central nervous system. Neuropeptides 36(2-3):209-220. Review

Drapeau E, Mayo W, Aurousseau C, Le Moal M, Piazza PV, Abrous DN (2003) Spatial memory performances of aged rats in the water maze predict levels of hippocampal neurogenesis. Proc Natl Acad Sci USA 100:14385-14390

Driscoll I, Sutherland RJ (2005) The aging hippocampus: navigating between rat and human experiments. Rev Neurosci 16:87-121

Efstratiadis A (1998) Genetics of mouse growth. Int J Dev Biol 42:955-976

Flurkey K, Papaconstantinou J, Miller RA, Harrison DE (2001) Lifespan extension and delayed immune and collagen aging in mutant mice with defects in growth hormone production. Proc Natl Acad Sci USA 98:6736-6741

Gage FH (2000) Mammalian neural stem cells. Science 287:1433-1438

Gehrmann J, Yao DL, Bonetti B, Bondy CA, Brenner M, Zhou J, Kreutzberg GW, Webster HD (1994) Expression of insulin-like growth factor-I and related peptides during motoneuron regeneration. Exp Neurol 128:202-210

Gheusi G, Cremer H, McLean H, Chazal G, Vincent JD, Lledo PM (2000) Importance of newly generated neurons in the adult olfactory bulb for odor discrimination. Proc Natl Acad Sci USA 97:1823-1828

Gibbons A (1998) Solving the brain's energy crisis. Science 280:1345-1347

Goldman SA (1998) Adult neurogenesis: from canaries to the clinic. J Neurobiol 36:267-286

Gould E, Reeves AJ, Fallah M, Tanapat P, Gross CG, Fuchs E (1999) Hippocampal neurogenesis in adult Old World primates. Proc Natl Acad Sci USA 96:5263-5267

Guarente L, Kenyon C (2000) Genetic pathways that regulate ageing in model organisms. Nature 408:255-262

Holzenberger M, Dupont J, Ducos B, Leneuve P, Geloen A, Even PC, Cervera P, Le Bouc Y (2003) IGF-1 receptor regulates lifespan and resistance to oxidative stress in mice. Nature 421:182-187

Ikeno Y, Bronson RT, Hubbard GB, Lee S, Bartke A (2003) Delayed occurrence of fatal neoplastic diseases in Ames dwarf mice: correlation to extended longevity. J Gerontol A Biol Sci Med Sci 58:291-296

Jarrard LE (1995) What does the hippocampus really do? Behav Brain Res 71:1-10

Jin K, Sun Y, Xie L, Batteur S, Mao XO, Smelick C, Logvinova A, Greenberg DA (2003) Neurogenesis and aging: FGF-2 and HB-EGF restore neurogenesis in hippocampus and subventricular zone of aged mice. Aging Cell 2:175-183
Kempermann G, Gast D, Gage FH (2002) Neuroplasticity in old age: sustained fivefold induction of hippocampal neurogenesis by long-term environmental enrichment. Ann Neurol 52:135-143

Kinney BA, Meliska CJ, Steger RW, Bartke A (2001a) Evidence that Ames dwarf mice age differently from their normal siblings in behavioral and learning and memory parameters. Horm Behav 39:277-284

Kinney BA, Coschigano KT, Kopchick JJ, Steger RW, Bartke A (2001b) Evidence that age-induced decline in memory retention is delayed in growth hormone resistant GH-R-KO (Laron) mice. Physiol Behav 72:653-660

Kirkwood TB, Austad SN (2000) Why do we age? Nature 408:233-238

Krzisnik C, Kolacio Z, Battelino T, Brown M, Parks JS, Laron Z (1999) The "little people" of the island of Krk revisited: etiology of hypopituitarism revealed. J Endocr Genet 1:9-19

Kuhn HG, Winkler J, Kempermann G, Thal LJ, Gage FH (1997) Epidermal growth factor and fibroblast growth factor-2 have different effects on neural progenitors in the adult rat brain. J Neurosci 17:5820-5829

Laron Z (2002) Growth hormone insensitivity (Laron syndrome). Rev Endocr Metab Disord 3:347-355

Liu JP, Baker J, Perkins AS, Robertson EJ, Efstratiadis A (1993) Mice carrying null mutations of the genes encoding insulin-like growth factor I (Igf-1) and type 1 IGF receptor (Igf1r). Cell 75:59-72

Lynch CD, Lyons D, Khan A, Bennett SA, Sonntag WE (2001) Insulin-like growth factor-1 selectively increases glucose utilization in brains of aged animals. Endocrinology 142:506-509

Markowska AL, Mooney M, Sonntag WE (1998) Insulinlike growth factor-1 ameliorates age-related behavioral deficits. Neuroscience 87:559-569

Masternak MM, Al Regaiey K, Bonkowski MS, Panici J, Sun L, Wang J, Przybylski GK, Bartke A (2004) Divergent effects of caloric restriction on gene expression in normal and long-lived mice. $\mathrm{J}$ Gerontol A Biol Sci Med Sci 59:784-788

Mathews LS, Hammer RE, Behringer RR, D'Ercole AJ, Bell GI, Brinster RL, Palmiter RD (1988) Growth enhancement of transgenic mice expressing human insulin-like growth factor I. Endocrinology 123:28272833

Miller MW, Nowakowski RS (1988) Use of bromodeoxyuridine-immunohistochemistry to examine the proliferation, migration and time of origin of cells in the central nervous system. Brain Res 457:44-52

Powell-Braxton L, Hollingshead P, Warburton C, Dowd M, Pitts-Meek S, Dalton D, Gillett N, Stewart TA (1993) IGF-I is required for normal embryonic growth in mice. Genes Dev 7:2609-2617

Pulford BE, Ishii DN (2001) Uptake of circulating insulinlike growth factors (IGFs) into cerebrospinal fluid appears to be independent of the IGF receptors as well as IGF-binding proteins. Endocrinology 142:213-220

Reinhardt RR, Bondy CA (1994) Insulin-like growth factors cross the blood-brain barrier. Endocrinology 135:1753-1761 
Rosenbloom AL, Almonte AS, Brown MR, Fisher DA, Baumbach L, Parks JS (1999) Clinical and biochemical phenotype of familial anterior hypopituitarism from mutation of the PROP1 gene. J Clin Endocrinol Metab 84:50-57

Seaberg RM, van Der KD (2003) Stem and progenitor cells: the premature desertion of rigorous definitions. Trends Neurosci 26:125-131

Shinar Y, McMorris FA (1995) Developing oligodendroglia express mRNA for insulin-like growth factor-I, a regulator of oligodendrocyte development. J Neurosci Res 42:516-527

Shors TJ, Miesegaes G, Beylin A, Zhao M, Rydel T, Gould E (2001) Neurogenesis in the adult is involved in the formation of trace memories. Nature 410:372-376

Smith TD, Adams MM, Gallagher M, Morrison JH, Rapp PR (2000) Circuit-specific alterations in hippocampal synaptophysin immunoreactivity predict spatial learning impairment in aged rats. J Neurosci 20:6587-6593

Sonntag WE, Xu X, Ingram RL, D'Costa A (1995) Moderate caloric restriction alters the subcellular distribution of somatostatin mRNA and increases growth hormone pulse amplitude in aged animals. Neuroendocrinology 61:601-608

Sorg BA, Smith MM, Campagnoni AT (1987) Developmental expression of the myelin proteolipid protein and basic protein mRNAs in normal and dysmyelinating mutant mice. J Neurochem 49:1146-1154

Sun LY, Al Regaiey K, Masternak MM, Wang J, Bartke A (2005a) Local expression of GH and IGF-1 in the hippocampus of GH-deficient long-lived mice. Neurobiol Aging 26:929-937

Sun LY, Evans MS, Hsieh J, Panici J, Bartke A (2005b) Increased neurogenesis in dentate gyrus of long-lived Ames dwarf mice. Endocrinology 146:1138-1144

Tatar M, Bartke A, Antebi A (2003) The endocrine regulation of aging by insulin-like signals. Science 299:1346-1351

Torres-Aleman I (1999) Insulin-like growth factors as mediators of functional plasticity in the adult brain. Horm Metab Res 31:114-119
Trejo JL, Carro E, Torres-Aleman I (2001) Circulating insulin-like growth factor I mediates exercise-induced increases in the number of new neurons in the adult hippocampus. J Neurosci 21:1628-1634

van Praag $\mathrm{H}$, Schinder AF, Christie BR, Toni N, Palmer TD, Gage FH (2002) Functional neurogenesis in the adult hippocampus. Nature 415:1030-1034

Vicario-Abejon C, Yusta-Boyo MJ, Fernandez-Moreno C, de Pablo F (2003) Locally born olfactory bulb stem cells proliferate in response to insulin-related factors and require endogenous insulin-like growth factor-I for differentiation into neurons and glia. J Neurosci 23:895-906

Wilkins A, Chandran S, Compston A (2001) A role for oligodendrocyte-derived IGF-1 in trophic support of cortical neurons. Glia 36:48-57

Woods KA, Camacho-Hubner C, Savage MO, Clark AJ (1996) Intrauterine growth retardation and postnatal growth failure associated with deletion of the insulinlike growth factor I gene. N Engl J Med 335:13631367

Yao DL, West NR, Bondy CA, Brenner M, Hudson LD, Zhou J, Collins GH, Webster HD (1995) Cryogenic spinal cord injury induces astrocytic gene expression of insulin-like growth factor I and insulin-like growth factor binding protein 2 during myelin regeneration. J Neurosci Res 40:647-659

Ye P, Carson J, D'Ercole AJ (1995) In vivo actions of insulin-like growth factor-I (IGF-I) on brain myelination: studies of IGF-I and IGF binding protein-1 (IGFBP-1) transgenic mice. J Neurosci 15:73447356

Zhou Y, Xu BC, Maheshwari HG, He L, Reed M, Lozykowski M, Okada S, Cataldo L, Coschigamo K, Wagner TE, Baumann G, Kopchick JJ (1997) A mammalian model for Laron syndrome produced by targeted disruption of the mouse growth hormone receptor/binding protein gene (the Laron mouse). Proc Natl Acad Sci USA 94:13215-13220

Zitnik G, Martin GM (2002) Age-related decline in neurogenesis: old cells or old environment? J Neurosci Res 70:258-263 